\title{
The Internal Structure of Sha-henda: A Morphological Perspective
}

\author{
Jiacing Ruan \\ Institute of Linguistics of National Chung Cheng University, Chiayi, Taiwan \\ Email: ac27037@gmail.com
}

Received 19 August 2014; revised 10 September 2014; accepted 16 September 2014

Copyright (C) 2014 by author and Scientific Research Publishing Inc.

This work is licensed under the Creative Commons Attribution International License (CC BY). http://creativecommons.org/licenses/by/4.0/

(c) (i) Open Access

\section{Abstract}

Sha-henda (殺很大) “kill-very-big” which is coined from an advertisement of an on-line game has been being recently very popular in Taiwan society. With the effect of this slogan, people tends to analogize more and more new expressions, for example: sheng-henda (省很大) "save-very-big", shui-henda (睡很大) “sleep-very-big", and etc. Until 2013, the quantity of the coined expressions is still increasing. In the previous studies of Shen (2009), Xiao (2009), Liu (2010) and Liu (2012) on the structure of $\mathrm{X}$-henda ( $\mathrm{X}$-很大), the structure is highly productive, involves an extreme or exaggerative meaning, is featured of rising tone, stress, and lengthening, and is initiated with a verb or an adjective. This present study argues henda in X-henda is a bound form (or a particle (助詞); Chao, 1979), similar to qilai (起來) in X-qilai or bude (不得) in X-bude, especially without objects or objects-preceding. With Distributed Morphology, a derivational analysis of the X-henda structure indicates that the function of henda intensifies the effect of sha to the extreme degree with rising tone, stress and lengthening to perform exaggeration on the object (in a sentence). The results may further contribute to grammaticalization analyses, verb-complement structure analyses and Chinese language teaching.

\section{Keywords}

Morphology, Distributed Morphology, Grammaticalization, Verb-Complement

\section{Introduction}

Sha-henda (殺很大) “kill-very-big” which is coined from an advertisement of an on-line game has been being 
recently very popular in Taiwan society. With the effect of this slogan, people tend to analogize more and more new expressions, for example: sheng-henda (省很大) “save-very-big”, shui-henda (睡很大) “sleep-very-big”, and etc. Until 2013, the quantity of the coined expressions is still increasing. A few papers (such as Liu, 2009; Xiao, 2009; Huang \& Lin, 2011; Liu, 2012) have discussed this topic. Especially, Xiao (2009) and Liu (2012) have viewed this structure as a construction (i.e., a form-meaning pair), regardless of derivations. However, although previous studies contributed valuable syntactic and semantic analyses to this structure, it seems none of them analyzed $X$-henda in terms of morphological perspective (especially a derivative perspective), since this structure is highly productive. This paper tries to analyze $X$-henda in two stages: First to provide a morphological observation in order to argue henda in $X$-henda is distinguished to be a bound form, and second to bring the bound form to a morphological analysis in $X$-henda structure with the framework of Distributed Morphology (Halle \& Marantz, 1993; Harley\& Noyer, 1999; Embick \& Noyer, 2005).

The organization of this paper is as follows. Section 2 is the discussion about previous studies on sha-henda (殺很大) “kill-very-big”. Section 3 argues henda as a bound form by morphological tests. Section 4 provides the theoretical background of Distributed Morphology and shows the analysis of the internal structure of $X$-henda. Section 5 shows the similarity and the difference of $X$-henda with other cases (such as $X$-qilai (X 起來) “start X” and $X$-bude (X 不得) “prohibited to X”) in Mandarin Chinese. Section 6 is the conclusion.

\section{Literature Review}

Xiao (2009) investigated the structure of $X$-henda with Construction Grammar (Goldberg, 1995). He discovered that henda in $X$-henda construction is not simply the composition of the adverbial hen and the adjective da but shows the meaning at an extreme degree. In this construction, $X$ is the variable of a verb or an adjective, even with a metaphoric use. Moreover, the phonological property of the $X$-henda construction is with the rising tone of the variable X, stressed and lengthening. Xiao (2009) specifically analyzed the verb variable with Vendler's (1967) four types of semantic classifications: activity, state, accomplishment and achievement, and found that $X$-henda construction appears in all the categories.

Liu (2010) revealed three linguistic properties of the structure of $X$-henda (X-很大). First, henda is originally a phrasal structure. Hen can be substituted for feichang (非常) “very”, or tebie (特別) “special”. However, hen$d a$ in $X$-henda is unchangeable and thus indivisible. Second, henda is originally preceded with a noun or a noun phrase. However, categories preceding henda in X-henda can be a verb or an adjective. Third, hen in henda is, in modern Chinese, originally as a syntactic function for grammaticality, and seldom has degree indication. However, hen in $X$-henda has an extreme, even exaggerative, meaning and $d a$ in $X$-henda strengthens hen.

Huang and Lin (2011) observed the compounding process of sha-henda (殺很大) “kill-very-big” in three stages of Separation, Transition and Compounding in terms of the collected data. In the Separation stage, the meanings of sha are literally predictable. In the Transition stage, the meanings of sha are hard to predict literally. In the Compounding stage, sha-henda is whole viewed as an indivisible unit. In the first two stages, the syntactic category of sha-henda remains to be VP $\left[[s h a]_{\mathrm{V}}+[\text { henda }]_{\mathrm{ADVP}}\right]_{\mathrm{VP}}$, while in the last stage it transform to ADJ $\left[[s h a]_{\mathrm{V}}+[\text { henda }]_{\mathrm{ADVP}}\right]_{\mathrm{ADJ}}$. They argued that sha-henda in the last stage has an extreme meaning, whatever positive or negative, when joining to an expression. Moreover, they also argued the whole unit of sha-henda as an adjective has more extreme status than henda.

Liu (2012) investigated sha-henda (殺很大) “kill-very-big” under the framework of Construction Grammar (Goldberg, 1995). Liu pointed out that this construction of $V$-henda is not exactly new, like du-henda (賭很大) “gamble-very-big” and kue-henda (虧很大) “lose-very-big”, before $X$-henda springs up. The crucial point is that $d a$ has been grammaticalized from the original content meaning-i.e., describing something that is large in weight, capacity, and others related to measurement— to becoming a function which emphasizes and modifies the degree of the effects of the inserted verb (i.e., intransitive verbs), the inserted adjective, or the degree of effects on the objects of the verb (i.e., transitive verbs). Furthermore, Liu (2012) observed that the highly productive structure of $X$-henda involves the meaning of extreme, which is the primary characteristic of this structure.

In summary of Xiao (2009), Liu (2010), Huang and Lin (2011) and Liu (2012) on the structure of X-henda (X-很大), the structure is highly productive, involves an extreme or exaggerative meaning, is featured of rising tone, stress, and lengthening (Xiao, 2009), and is initiated with a verb or an adjective. Although they offered valuable analyses on this structure, all of the previous studies analyzing $X$-henda much more focus on the syn- 
tactic/semantic perspective. However, before moving to syntactic or semantic analyses, a morphological analysis should be provided first for later advanced syntactic or semantic analyses. Furthermore, the studies (Xiao, 2009; Liu, 2012) applying Construction Grammar (Goldberg, 1995) emphasize the analyses of X-henda construction. In the present paper, Distributed Morphology (Halle \& Marantz, 1993; Harley \& Noyer, 1999; Embick \& Noyer, 2005), "a constructionalist realizational approach to morphology" (Mavrogiorgos, 2010: p. 66), has been applied to dig out how $X$-henda construction is structured. This present study first argues henda in $X$-henda is a bound form (or a particle (助詞); Chao, 1979), in which hen and da have already lost their original meanings. Henda in $X$-henda should be analyzed without referring to its components ${ }^{1}$ because it is indivisible like qilai (起來) in $X$-qilai or bude (不得) in $X$-bude, especially without objects or objects-preceding, and second applies Distributed Morphology to analyze the structure.

\section{The Morphological Observations and Tests of X-Henda ${ }^{2}$}

In this section, henda in sha-henda (殺很大) “kill-very-big” is argued as a bound form (or a particle) which functions intensifying the effect of the verb to an extreme extent, through morphological observations and tests. The results of the observations and tests in this section are as the basics to be integrated to the analysis of Distributed Morphology in Section 4.

First, it is prerequisite to observe the behaviors of original henda in Mandarin Chinese, as can be seen in (1):

(1) a) Zhege fangzi henda 這個 房子 很大

This house is very big.

b) Lang henda

浪 很大

The wave is very big.

c) Nijia you henda de fangjian

你家 有 很大 的 房間

There is a very big room in your house.

In examples in (1), henda may serve as a predicate, like in (1a) and (1b), or as a modifier such as in (1c). In addition, henda in (1a) and (1b) can be transformed from sentences to phrases, such as in (2):

(2) a) Zhege henda de fangzi

這個 很大 的 房子

This very big house.

b) henda de lang

很大 的 浪

Very big wave.

It is very clear that henda in (1a), (1b), (2a), and (2b) is a phrasal structure of [adverb + adjective]. Insertions of modifiers are allowed, such as kuan (寬) “wide” and ju (巨) “huge” in (3):

(3) a) Zhege hen kuanda de fangzi 這個 很 寬大 的 房子

This wide house

b) Hen juda de lang

很巨大 的浪

Very huge wave

From examples (1), (2) and (3), henda is a phrasal structure. However, the examples in (4) cannot function like the behaviors in (1), (2) and (3):

${ }^{1}$ One might still find out the occurrences of sha-feichangda (殺非常大), “kill-very-big” through Google Search. However, the structure of $X$-henda is not totally initiated with sha, but other expressions are all needed to be considered. With a broader view, productivities of

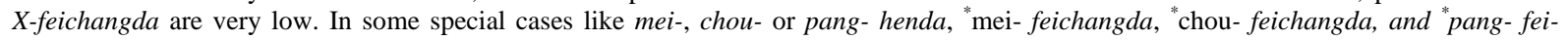
changda are all unacceptable.

${ }^{2}$ All the examples in this article except cited data are from the Internet with Google Search during 2011 to 2014. 
(4)

\begin{tabular}{|c|c|c|c|}
\hline a. du henda & e. du de henda & i. du le henda & m. *du bu du henda \\
\hline 賭很大 & 賭的很大 & 賭了很大 & *賭不賭很大 \\
\hline b. kui henda & f. kui de henda & j. kui le henda & n. * kui bu kui henda \\
\hline 虧很大 & 虧的很大 & 虧了很大 & "雐不虧很大 \\
\hline c. ${ }^{*}$ henda de du & g. du henda le & k. du hen-xiao/du buda & o. du (de) henda henda \\
\hline${ }^{*}$ 很大的賭 & 賭很大了 & 賭很小/賭不大 & 賭(的)很大很大 \\
\hline d. *henda de kui & h. kui henda le & l. du/kui (de) feichangda & p. kui (de) henda henda \\
\hline *很大的虧 & 虧很大了 & 賭/虧 (的) 非常大 & 虧(的)很大很大 \\
\hline
\end{tabular}

Examples in (4) show the tests of $d u$ and kui. In (4), (4a) and (4b) cannot be transformed into phrases like examples in (3), such as in (4c) and (4d) $)^{3}$. (4e), (4f), (4i) and (4j) are examples indicating that du-henda or kui-henda acts like the phrasal structure [verb + de/le + adverb (henda)]. Concerning the meaning of henda, examples in (1) to (3) conserve the original meaning of henda, in which henda refers to size, weight or others to things. However, in (4), henda indicates the degree of the verb rather than the same meaning in (1) to (3). Instead, it becomes the function of henda which intensifies the effect of the verb. The substantial difference is that henda modifies nouns in (1) to (3), while modifies verbs in (4). henda in the examples (4) may be grammaticalized because it no longer keeps its original meaning. Liu (2012) indicates that $X$-henda is not a new structure because (4a) and (4b) have already been using in Mandarin Chinese. However, the tests in (5) may contradict to Liu's statement:

(5)

\begin{tabular}{|c|c|c|}
\hline a. sha henda & e. sha henda le & i. * sha bu sha henda \\
\hline 殺很大 & 殺很大了 & *殺不殺很大 \\
\hline b. " henda de sha & f. " sha hen (kuan/guang/ju) da & j. ${ }^{*}$ sha de henda henda \\
\hline *很大的殺 & *殺很 (廣/寬/巨) 大 & *殺的很大很大 \\
\hline c. ${ }^{*}$ sha de henda & g. " sha henxiao/*sha buda & k. sha henda henda \\
\hline *殺的很大 & *殺很小/殺不大 & 殺很大很大 \\
\hline d. ${ }^{*}$ sha le henda & h. * sha feichangda & \\
\hline *殺了很大 & *殺 非常大 & \\
\hline
\end{tabular}

Examples in (5) were tested like in (4). In (5), the structure is first argued to be a different structure from the ones in (1), (2), (3) and (4). The structure of sha-henda seems to disallow any insertion from the observation. In addition, henda in some of cases in (1) to (4) can be substituted for henxiao (很小) or others, while examples in (5) can not be. Furthermore, henda in (4) does not have the extreme meaning such as in (5) as well, because there is a much deeper degree modifier feichangda (非常大) which can replace henda in most of the examples in (4). As for the structure of V-not-V, V-not-V is prohibited in both (4) and (5), while both (4) and (5) accept the reduplicate form (i.e., (4o), (4p), (5j) and (5k)) of henda. However, any insertion is still disallowed in (5), not in (4).

Second, whether henda (很大) is free or bound is addressed. In examples (4), henda functions as an adverb which can occur freely, i.e., in any insertion, substitution or transformation. In (5), it is argued that henda in $X$-henda (X 很大) is not free for two reasons in (6).

(6) a) henda in sha-henda "kill-very-big" does not function as "extreme" unless a verb is inserted.

b) henda in sha-henda "kill-very-big" disallows insertion, substitution or transformation.

For (6a), if sha is removed, henda does not have function which provides the extreme extent. As for (6b), henda cannot behave like in (2)-(4), which indicates that henda must immediately follow sha. According to the arguments above, sha and henda are in such a conjoint structure. Comparing with examples in English in (7), it 
may be able to say that henda is not a free form but acts like a bound form. Since henda in $X$-henda is not free, regarding sha-henda (殺很大) "kill-very-big” as an adverb incorporation compound seems to be impossible, despite the such similar syntactic structure in sha-henda, i.e., henda modifies sha. The brief summary about henda is in Table 1.

(7) a) It is able to do.

b) It is do-able.

c) ${ }^{*}$ It is do-very-able.

d) ${ }^{*}$ It is able-do. e) henda de fangzi/fangzi henda (很大的房子/房子很大)

f) sha henda (殺 很大)

g) ${ }^{*}$ sha de henda (*殺 的 很大)

h) *henda sha (*很大 殺)

Third, since sha-henda (殺很大) "kill-very-big” is conventionally coined in the society, it is indispensible to consider whether sha-henda is an idiomatic phrase ${ }^{4}$. Chen (1991) indicates that the properties of idioms are now multi-perspectives, but it may still be possible to have an examination given the following aspects (Chen 1991):

(8) a) Given the structure, idioms have the property of stability.

b) Given the meaning, idioms have the property of alternation.

c) Given the function, idioms are equivalent to words.

Take kaiyieche (開夜車) “stay up late”, from Chen (1991) as an example. In (8a), the stability is a shared property among idiom phrases and set phrases. However, the idiom phrases are more flexible than set phrases such as in (9) (adopted from Chen 1991):

(9) a) kaiyieche -> kai le zhengzheng yigeyue de yieche 開夜車 $\rightarrow>$ 開了整整一個月 的 夜車

b) kaiyieche -> yieche buyao kai de taiduo 開夜車 $\rightarrow$ 夜車 不要 開 的 太多

c) tuo houtue $->$ che houtue $->$ la houtue 拖後腿 $\rightarrow>$ 扯後腿 $\rightarrow>$ 拉後腿

In (9), the idiom phrase kaiyieche can be inserted with other expressions, even putting a partial to a distant position as in (9b). Although idiom phrases can be flexibly used, they still have the fixed forms (i.e., kaiyieche is the fix form and others in (9a) or (9b) are the flexible use). In (8b), this particularly refers to the compositionality. The meaning of an idiomatic phrase cannot be interpreted from its literal meaning. For example in (9a), kaiyieche (開夜車) exactly does not refer to “driving a car in the night” but”processing or working for due time of a purpose”. In (8c), idioms are used as words in a sentence. According to (8), sha-henda (殺很大) "kill-very-big"seems not to be idiom-phrase-like.

Analogizing by considering (8) and (9), sha-henda (殺很大) “kill-very-big” may fit (8a), may not be used as in (9a) and (9b), but may be possibly used like in (9c). (10) is the illustrations:

(10) a) sha henda $->$ sha le yizhizhu henda 殺很大 -> 殺了一隻豬很大

b) sha henda $->$ * henda buyao sha de taiduo 殺很大 ->* 很大 不要 殺 的 太多

c) sha henda -> sheng henda -> shui henda 殺 很大 -> 省 很大 -> 睡 很大

Table 1. The brief summary of different henda in Mandarin Chinese.

\begin{tabular}{cccc}
\hline & henda 1 & henda 2 & henda 3 \\
\hline Category & Adjective & Adverb & Bound form \\
Modification & Noun & Verb & Verb \\
Content/function & Content & Function & Function \\
Distribution Free/restricted & Free & Free & Restricted \\
Meaning & Description of size, weight & Description of a gradual & Description of a non-incrementally \\
& and other measurements. & degree of the verb. & extreme (or exagerative) degree of the verb \\
\hline
\end{tabular}

${ }^{4}$ In this paper, for the purpose of distinction between the English usage of “idiom phrases” for both guanyongyu (慣用語) and chengyu (成 語), the term “idiom phrase” refers to guanyongyu and “set phrase” refers to chengyu/shuyu (熟語). 
As for (8b), sha-henda still conserves its literal meaning, i.e., the meaning of sha does not change either ${ }^{5}$, such in (11):

(11) a) xianshi xiaji sha henda (限時 夏季 殺 很大).

b) gongchengshi que henda (工程師 缺 很大).

Regarding (8c), sha-henda is also used as a word in a sentence. In summary, sha-henda totally conforms with (8c), half conforms with (8a), and does not conform with (8b). It seems there are few differences between sha-henda and idiomatic phrases. However, the high productivity may determine the most important difference between the two. The bound form henda can be initiated with verbs or adjectives to coin many expressions, but idiomatic phrases like kaiyieche do not have the obvious property.

Fourth, the structure of sha-henda (殺很大) “kill-very-big” may also resemble to the verb-complement structure in Mandarin Chinese. For example, jian-bude (講不得) or qiao-buqi (燋不起) is mentioned as “it seems therefore also plausible to consider these lexemes as having disyllabic suffixes”" (Yip, 2000: p. 85), such as jian-de (講得)/jian-bude (講不得), and qiao-deqi (焦得起)/qiao-buqi (燋不起). Yip (2000) also mentions that this is not an economical analysis. However, it is still possible for sha-henda to be analyzed as a V-bound form. As can be seen in (12), both chi-bude and sha-henda are indivisible (i.e., (12c), and (12f)). More comparisons are in Section 5.
a. zhegeku ni chibude
d. xiaji dianqi sha henda
這個苦 你 吃不得
夏季 電器 殺 很大
b. ni chibude zhegeku
e. "sha henda xiaji dianqi
你 吃不得 這個苦
"殺 很大 夏季 電器
c. ${ }^{*}$ ni chi zhegeku bude
f. *xiaji sha dianqi henda
*吃這個苦不得
*夏季 殺 電器 很大

Fifth, the structure of $X$-henda allows inserting adjectives such as examples in (13):

(13) a) mei-henda 美很大;

b) chou-henda 醜很大;

c) pang-henda 胖很大.

In (13), henda in mei-henda, chou-henda and pang-henda does not change the meaning of mei, chou or pang. By inserting mei, chou or pang, $X$-henda provides the function extending the effect of mei, chou or pang to an extreme or exaggerative degree. The new examples, however, seem to demolish V+henda. According to Chomsky (1974), verbs and adjectives have $[+\mathrm{v}]$ category feature. It may be better to call this structure as $+\mathrm{V}$-henda. Consequently, the structure of sha-henda (殺很大) “kill-very-big” or X-henda may be generalized as follows in (14). After discussing the properties of the $X$-henda structure, it is further analyzed with Distributed Morphology in later sections.

(14) The generalization of [+V-henda]

[category $[+\mathrm{v}]+$ bound form (henda) $]_{\text {verb/adjective (extreme or exaggerative) }}$

(Any category which has a feature $[+\mathrm{v}]$ and is inserted to the bound form henda becomes a verb or an adjective with extreme or exaggerative effects).

\section{The Analyses with Distributed Morphology}

Distributed Morphology “a constructionalist realizational approach to morphology” (Mavrogiorgos, 2010: p. 66), has been applied to dig out how the construction of $X$-henda is structured.

Considering a word is assembled by syntactic operations, the syntax-driven approach Distributed Morphology (Halle \& Marantz, 1993; Harley \& Noyer, 1999; Embick \& Noyer, 2005), henceforth DM, has three lists as ${ }^{5}$ The fruitful meanings of sha are not only presented in $X$-henda structure, but also in any other structures.

${ }^{6}$ Liu (2010) also mentions henda in X-henda is a fixed suffix. However, a disyllabic bound form analyzed to be a suffix is very rare in Mandarin Chinese. Thus, the preset article still terms henda in X-henda is a bound form. 
theoretical basics as in Figure 1 (reedited from Embick \& Noyer, 2005: p. 10).

DM hypothesizes the nonexistence of a lexicon or word. Consequently, any formative (equivalent to a word) is composed with three lists: derived from syntactic derivations with Syntactic Terminals, spelt out with The Vocabulary with Vocabulary Items to Syntactic Terminals and generated with the combining the two derivationsmentioned with The Encyclopedia for interpretations. The three lists are explained below (15) with Figure 2 (reedited from Harley \& Noyer, 1999: p. 3).

(15) List A. The Syntactic Terminals: Roots, Abstract Morphemes

List B. The Vocabulary: Vocabulary Items

List C. The Encyclopedia: Features of semantic information or non-linguistic knowledge

In Embick and Noyer (2005), Roots, also l-morpheme (Harley \& Noyer, 1999), are items such as $\sqrt{ }$ CAT, $\sqrt{ } \mathrm{DOG}$ and others, with phonological features but without any syntactic features. The Abstract Morphemes, also f-morpheme ${ }^{7}$ (Harley \& Noyer, 1999), are items with syntactic but non-phonetic features such as [Past] or [pl]. The Vocabulary Items are the phonological exponents which are assigned to the Syntactic Terminals. As for The Encyclopedia, the features of non-linguistic knowledge are assigned to the combination of LF and PF, as in Figure 2.

With DM, $X$-henda can thus be analyzed as in Figure 3.

In Figure 3, (from left to right), the first $\mathrm{v}^{8}$ is formed by inserting sha (as a $\mathrm{v}$ category). Then, the $\mathrm{v}$ of sha is merged with henda to form another $\mathrm{v}$, in which henda intensifies the effect of sha. Third, henda moves to DegP and acquires the features [+extreme] and [-comparative] because it does not have a comparative form. These features like [+intensive], [+extreme] and [-comparative] are later spelt out with phonological observations as in Xiao (2009): the structure of $X$-henda has phonological features of rising tone, stress and lengthening. Thus, the function of henda intensifies the effect of sha to the extreme degree (The first stage: Access to Syntactic Terminals) with rising tone, stress and lengthening (The second stage: Access to The Vocabulary) to perform exaggeration (The third stage: Access to The Encyclopedia) on the object (in a sentence). The construction of $\mathrm{X}$-henda can thus be outline as (16):

(16) $\sqrt{ } \operatorname{Root}(-h e n d a)-[+$ intensive]-henda-[+extreme,-comparative]

In addition, several differences between Construction Grammar and Distributed Morphology need to be clarified. The meaning is formed at different stages. For Construction Grammar, it is the construction itself that has a meaning. For Distributed Morphology, the meaning is formed after PF and interpreted in the Encyclopedia. Therefore, (16) has formed the meaning in Construction Grammar, while (16) has as well if Vocabulary Itemsare inserted in Distributed Morphology.

\section{Comparison to X-qilai ( $X$ 起來) and X-bude ( $X$ 不得) ${ }^{9}$}

After the DM analysis of the structure of $X$-henda, the present study further finds that the structure of $X$-henda is

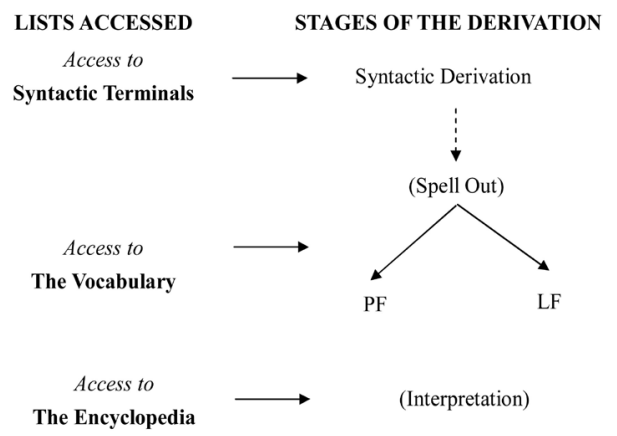

Figure 1. The Grammar and the Lists in Distributed Morphology.

\footnotetext{
${ }^{7} \mathrm{~L}$-morpheme is for the lexical morphemes, while f-morpheme is for the functional morphemes.

${ }^{8}$ The little v here refers to categories with the feature $[+v]$. In other words, roots inserted in this structure become only verbs or adjectives. This prevents false predictions of [-v] insertion, such as fangzi henda (房子很大), “the house is big”.

${ }^{9}$ This article lightly addresses qilai, and bude because the purpose is only to prove the similarity among $X$-henda, $X$-qilai and $X$-bude with the productivity and the position when receiving an object in syntax.
} 


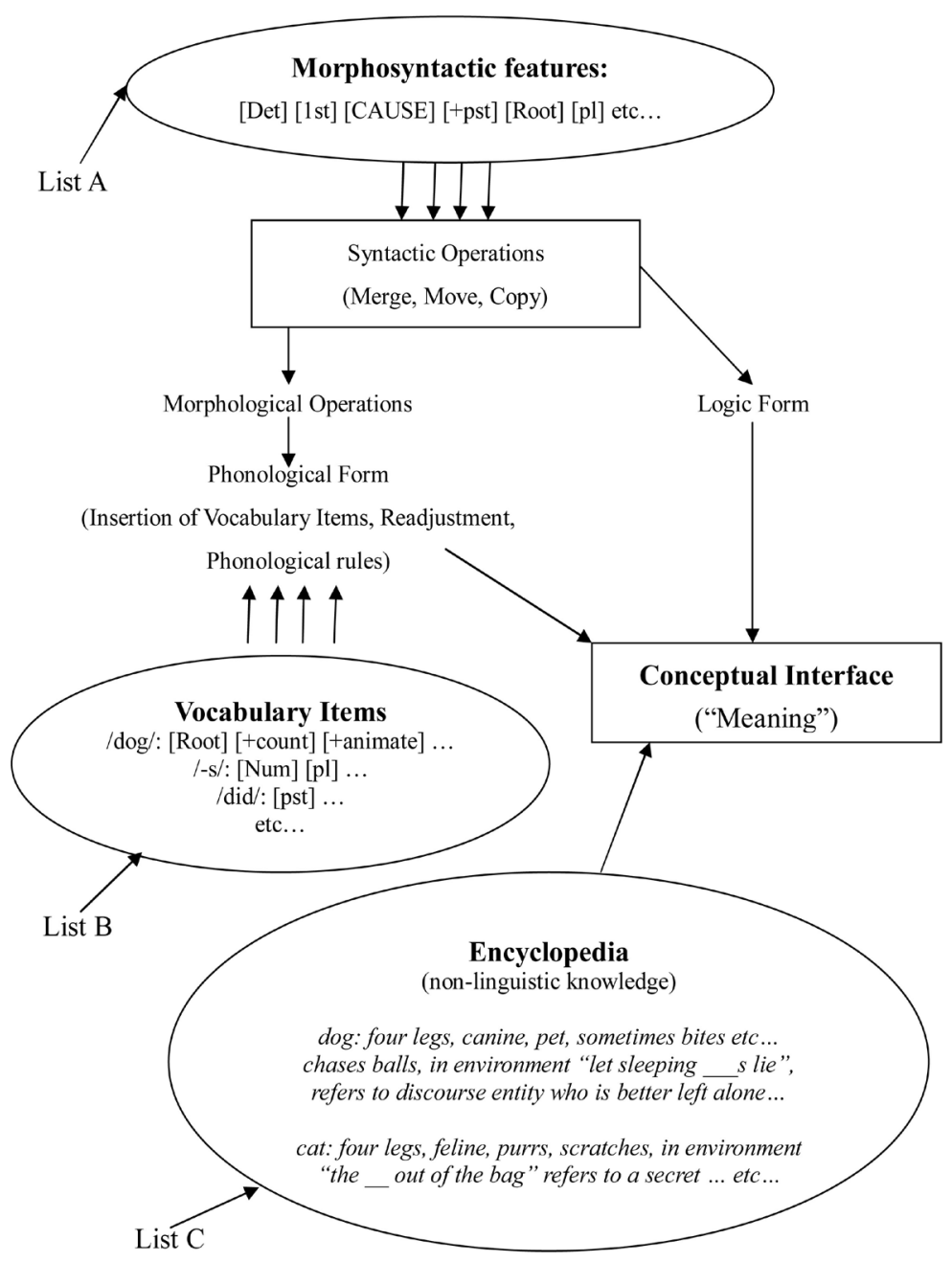

Figure 2. The theoretical structure of Distributed Morphology.

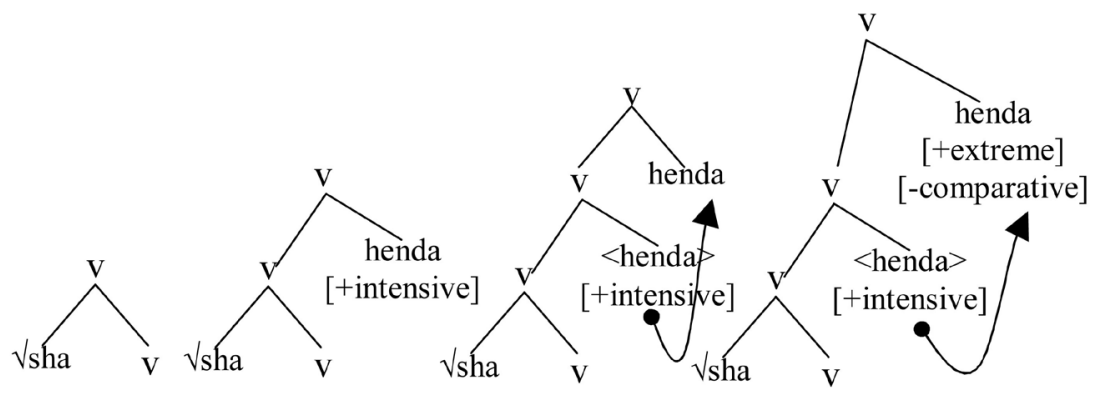

\section{Figure 3. The syntactic derivations of sha-henda (殺很大) “kill-very-big” with DM.}

very similar to the verb-complement structure, such like $X$-qilai or $X$-bude as in Table $2^{10}$.

Qilai, bude and henda are all grammaticalized from their original meanings to functions. In addition, all of them are from free to bound to become verb-complement structures. In Table 2, all the three bound forms accept a verb or an adjective to be the variable X. X-qilai does not accept SOV or SVO when there is an object following. The object is inserted between qi and lai, such as chi-qi fan lai (吃-起飯來) “start eating rice”. As for $X$-bude, Shen (2010) has argued that bude is grammaticalized in four stages: a negative form of $d e$, a modal aux-

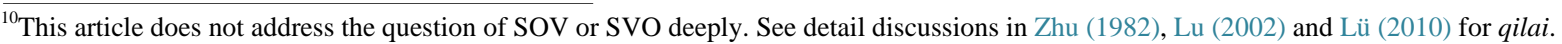


Table 2. The comparison of $X$-qilai, $X$-bude and $X$-henda.

\begin{tabular}{ccccc}
\hline & $\mathrm{X}$ as verb & $\mathrm{X}$ as adjective & SOV & SVO \\
\hline$X$-qilai & Yes & Yes & No & No \\
$X$-bude & Yes & Yes & Yes & No \\
$X$-henda & Yes & Yes & Yes & No \\
\hline
\end{tabular}

iliary, a particle and a word. For example, they are bude dajia zhichi (不得大家支持) “does not obtain the support from people”, bude chifan (不得吃飯) “unable to eat” or “prohibited to eat”, la de dongxi chibude (辣的東 西吃不得) “spicy food is unable to eat” or “spicy food is prohibited to eat”, and guaibude (怪不得) “no wonder”. In Table 2, bude in $X$-bude refers to the particle stage, so it does not accept SVO. In all, $X$-bude and $X$-henda are much more similar than $X$-qilai and $X$-henda.

From the analyses above, Liu (2012) argued that henda in $X$-henda refers to large quantity being much closer with the objects in a discourse context, especially when $X$ is a transitive verb. However, from the comparisons of $X$-qilai, $X$-bude and $X$-henda, it can be found that the bound forms qilai, bude and henda are much closer with the inserted verbs or adjectives. It is the cause-effect phenomenon that brings the two viewpoints. In the example, dianhuafei sheng-henda (電話費省很大) “save a lot of call fees”, henda intensifies the effect of sheng to the extreme degree on the object dianhuafei, and the quantity of saving is thus enlarged.

\section{Conclusion}

This current paper contributes morphological observations and analyses to the structure $X$-henda incorporating Distributed Morphology. Sha-henda (殺很大) “kill-very-big” or X-henda has been argued to be a different structure from Liu (2012) suggested. The structure of sha-henda seems not identical to the structures of du-henda (賭很大) “gamble-very-big” or kui-henda (虧很大) “lose-very-big”. In addition, henda is analyzed and argued to be a bound form which intensifies the effect of the inserted verb or adjective to an extreme degree on objects. Moreover, henda in $X$-henda is a similar structure of $X$-qilai or $X$-bude. The results further contribute to grammaticalization analyses, verb-complement structure analyses and Chinese language teaching.

\section{Acknowledgements}

The earlier version of this paper was presented in National Conference on Linguistics (NCL), held at National Hsinchu University of Education, Hsinchu, Taiwan on 2010/11/12-13. Many thanks go to audience who gave valuable suggestions or comments. Many thanks go to anyone who has ever reviewed this paper for me. Special thanks also go to the anonymous reviewers of the Open Journal of Modern Linguistics for their comments. I am personally responsible for any insufficiency.

\section{References}

Chao, Y. R. (1979). A Grammar of Spoken Chinese. Beijing, China: Commercial Press.

Chen, G.-L. (1991). Zhongguo Guanyongyu [Chinese Idioms]. Shanghai: Shanghai Wenyi Chubanshe.

Chomsky, N. (1974). The Amherst Lectures, unpublished lecture notes distributed by Documents Linguistiques, University of Paris VII.

Embick, D. \& Noyer, R. (2005). Distributed Morphology and the Syntax/Morphology Interface. http://www.ling.upenn.edu/ embick/interface.pdf

Goldberg, A. E. (1995). Constructions: A Construction Grammar Approach to Argument Structure. Chicago \& London: The University of Chicago University Press.

Halle, M. \& Marantz A. (1993). Chapter 3: Distributed Morphology and the pieces of Inflection. In K. Hale, \& J. Keyser, (Eds.), The View from Building 20 (pp. 111-176). Cambridge, MA: MIT Press

Harley, H. \& Noyer, R. (1999). Distributed Morphology. Glot International, 4, 3-9.

Huang, C.-W, \& Lin, H. -J. (2011). The Compounding of Taiwan Vogue Word “Sha Hen Da”. National Central University Journal of Humanities, 48, 163-203.

Liu, L.-X. (2009). Xiaoyi Wanglu Chuanbo Xinyu “X-henda” [A Discussion about a New Coinage Expression "X-henda”]. Journalism Lover, 5, 151. 
Liu, X.-Y. (2012). Yuyan De Chuangxin Yu Yingyong—-Taiwan Guoyu “X-henda” Jiegou Yanjiu [The Creativity and Application of Language - the Study of Taiwan Chinese "X-henda”]. Modern Chinese, 4, 58-62.

Lu, J. M. (2002). Concerning the Verbal Complement of Direction and the Position of Object. Chinese Teaching in the World, 1, 5-18.

Lü, S. X. (1999). Xiandai Hanyu Babai Ci: Zengdingban [The 800 Words of Modern Chinese]. Bejing: The Commercial Press.

Mavrogiorgos, M. (2010). Clitics in Greek: A Minimalist Account of Proclisis and Enclisis. Amsterdam: John Benjamins Publishing. http://dx.doi.org/10.1075/la.160

Shen, H. R. (2010). Xiandai Hanyu Liangzhong “Bu De” Jiegou [The Two Structures of "Bade” in Modern Chinese]. Modern Chinese, 1, 43-45.

Vendler, Z. (1967). Linguistics in Philosophy. Ithaca: Cornell University Press.

Xiao, J. J. (2009). Taiwan Gongtongyu “X Henda” Jushi Chutan [The Exploration of the Construction "X Henda” in Taiwan Chinese]. The 59th Annual Conference of the Chinese Linguistic Society of Japan, Sapporo, 24-25 October 2009.

Yip, P. C. (2000). The Chinese Lexicon: A Comprehensive Survey. New York: Routledge.

Zhu, D. X. (1982). Yufa Jiangyi [Grammar Handout]. Beijing: The Commercial Press. 
Scientific Research Publishing (SCIRP) is one of the largest Open Access journal publishers. It is currently publishing more than 200 open access, online, peer-reviewed journals covering a wide range of academic disciplines. SCIRP serves the worldwide academic communities and contributes to the progress and application of science with its publication.

Other selected journals from SCIRP are listed as below. Submit your manuscript to us via either submit@scirp.org or Online Submission Portal.
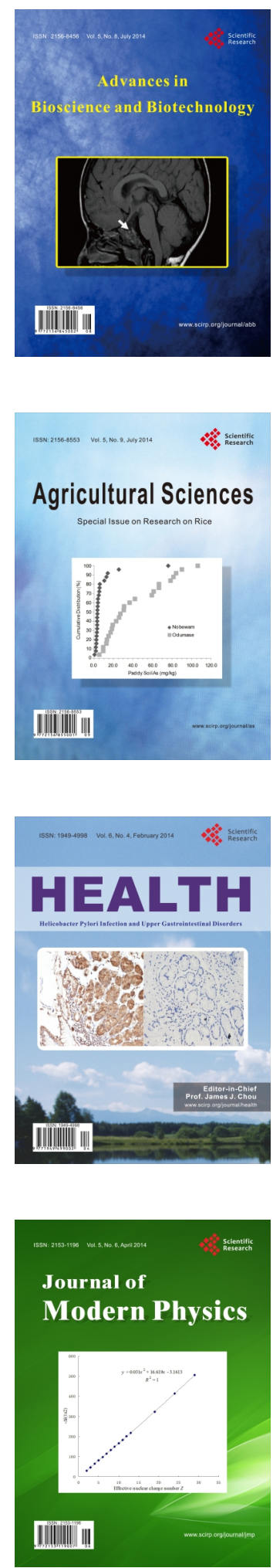
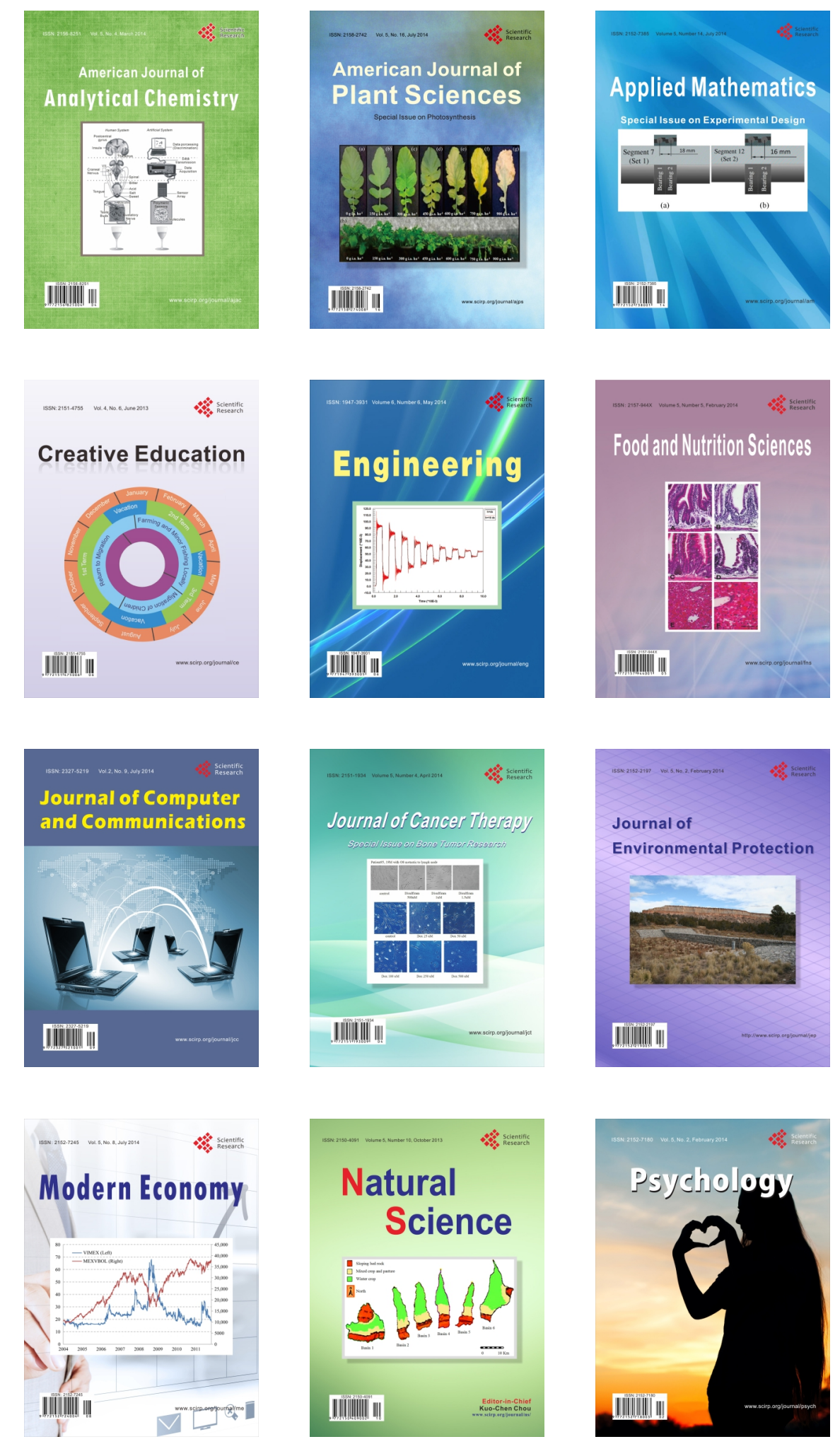